\title{
Thin Films of AuCuAl Shape Memory Alloy for Use in Plasmonic Nano-actuators.
}

\author{
Vijay Bhatia ${ }^{1}$, Gordon Thorogood ${ }^{2}$, Annette Dowd ${ }^{1}$ and Michael B. Cortie ${ }^{1}$ \\ ${ }^{1}$ Institute for Nanoscale Technology, University of Technology Sydney, PO Box 123, Broadway \\ NSW 2007, Australia \\ ${ }^{2}$ Institute of Materials Engineering, Australian Nuclear Science and Technology Organisation, \\ PMB 1, Menai NSW, 2234, Australia
}

\begin{abstract}
We describe the fabrication and structure of nanoscale thin films of $\beta$ phase shape memory alloys with the nominal atomic stoichiometry $\mathrm{Au}_{7} \mathrm{Cu}_{5} \mathrm{Al}_{4}$ (corresponding to $5.8 \mathrm{wt} \%$ Al). These alloys possess properties that suggest they could be used in nanoscale actuators. The films described here are between 20 and $50 \mathrm{~nm}$ thick which is below the thickness at which some other shape memory alloys cease to transform. However, microstructural and X-ray studies confirm that the coatings still exhibit the displacive transformations that are a prerequisite for the shape memory effect.
\end{abstract}

\section{INTRODUCTION}

Shape memory alloys (SMAs) possess the ability to revert back to an initial shape after being deformed. This is achieved through a reversible, displacive phase change in which the atom positions are shifted in a diffusionless process from an austenitic structure to a martensitic structure, or vice versa. $\beta$ phase shape-memory alloys with stoichiometries in the vicinity of $\mathrm{Au}_{7} \mathrm{Cu}_{5} \mathrm{Al}_{4}$ exhibit high X-ray and electron absorption, are reasonably resistant to oxidation, have convenient transformation temperatures in the bulk form, and have a dielectric function suitable for the generation of a moderately strong localized surface plasmon resonance. Therefore, we have sought to fabricate nanoscale opto-mechanical actuators from this material. Here we discuss the deposition of nanoscale films of this material and their characterization.

$\mathrm{Au}_{7} \mathrm{Cu}_{5} \mathrm{Al}_{4}$ (sometimes called 'Spangold' [1]) is a less well-known example of a SMA. It has been shown to be relatively resistant to aging compared to its copper-based counterparts and has been previously studied in its bulk form [2-12]. However no work has been done on any thin film or nanostructured properties. On the other hand, the TiNi SMA ('Nitinol') has been extensively studied over a wide range of size scales and for use in many different applications. Use of TiNi in nano-actuators has been limited to date, due to problems experienced when producing films of less than $100 \mathrm{~nm}$ thickness [13, 14]. Oxidation is one of the factors that limits the shape memory effect (SME) in very thin films of TiNi because it changes the composition of the alloy to the point where it is no longer capable of exerting an SME. In contrast, $\mathrm{Au}_{7} \mathrm{Cu}_{5} \mathrm{Al}_{4}$ is quite resistant to oxidation due to its high gold content and is therefore a good candidate for the fabrication of nanoscale thin films. The other advantage of $\mathrm{Au}_{7} \mathrm{Cu}_{5} \mathrm{Al}_{4}$ is its optical properties, as mentioned above. The plasmonic heating that would accompany a localized surface plasmon resonance in a suitably designed nanostructure could be used to drive the actuator through its martensite to austenite transformation. Plasmonic heating has been investigated before for medical applications [15] but the presently proposed use appears to be novel. 


\section{EXPERIMENTAL DETAILS}

An alloyed sputtering target of 58 at. $\% \mathrm{Au}-42$ at $\% \mathrm{Cu}$ was produced by melting the pure elements in an inert atmosphere and casting into a graphite mould. This composition was chosen because it provides the same ratio of $\mathrm{Au}$ and $\mathrm{Cu}$ as in the Spangold SMA. A series of thin films of varying $\mathrm{Al}$ content, and hence varying electron-to-atom (e/a) ratio, was produced in a twotarget sputtering configuration using the alloy target and an $\mathrm{Al}$ target. The locus of thin film compositions follows $\left(\mathrm{Au}_{0.58} \mathrm{Cu}_{0.42}\right)_{1-x} \mathrm{Al}_{x}$ and the range $0.13<\mathrm{x}<0.25$ at\% $\mathrm{Al}$ (corresponding to 2.8 to $6 \mathrm{wt} \% \mathrm{Al}$ ) produces $\beta$ phase. The locus is shown in figure 1(a) and includes the standard $\mathrm{Au}_{7} \mathrm{Cu}_{5} \mathrm{Al}_{4}$ composition. Within the $\beta$ phase region, these film compositions fall close to the 76 wt\% isopleth of the Al-Au-Cu ternary which is also known, figure 1(b). Initially films were deposited at room temperature but, in order to induce crystallisation, films were either postannealed in an inert atmosphere for 1 to $5 \mathrm{hrs}$ or deposited at $400^{\circ} \mathrm{C}$. A range of sputtering times were used from 4 to 20 mins to produce different thicknesses. Films were simultaneously deposited on both glass and Si (111) substrates, which were rotated to increase homogeneity.

(a)

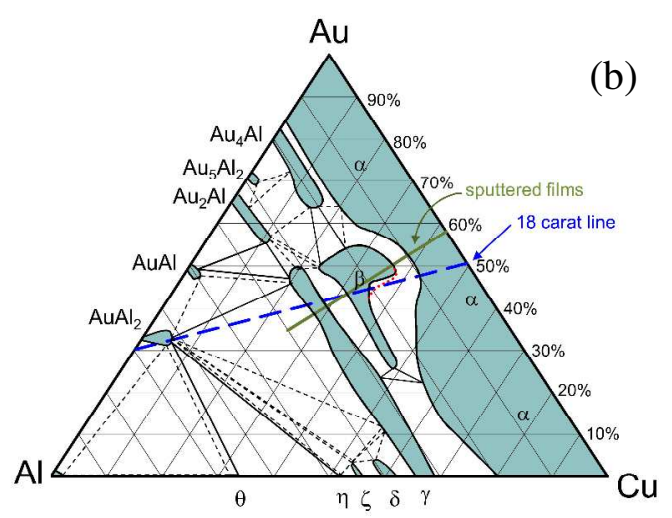

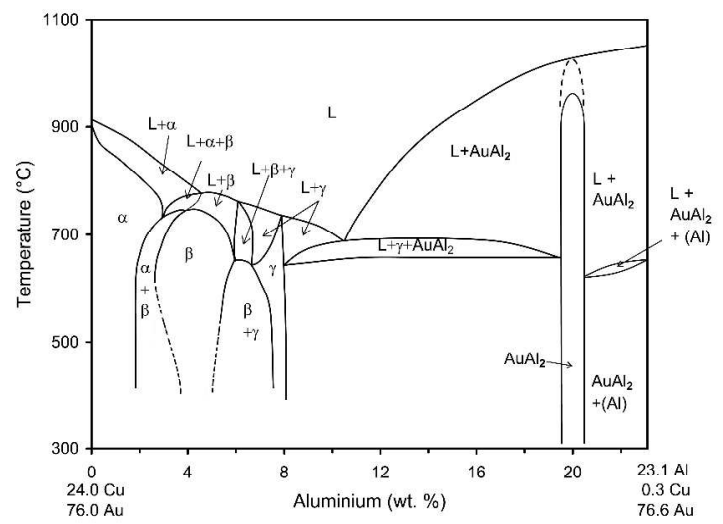

Figure 1. Phase relationships in the $\mathrm{Al}-\mathrm{Au}-\mathrm{Cu}$ ternary system. (a) $500^{\circ} \mathrm{C}$ isothermal section showing location of $75 \mathrm{wt} \%$ (18 carat) pseudo-binary section and locus of compositions produced in the present work by sputtering. (b) Pseudo-binary section at $76 \mathrm{wt} . \% \mathrm{Au}$. The dotted lines indicate that prolonged annealing studies are likely to reveal some constriction in the $\beta$ phase field at lower temperatures. (Modified and redrawn from refs. [4], [16] and [2]).

X-ray reflectometry (XRR) was used to measure the thickness and quality of the deposited films, using Motofit least squares fitting software[17] to interpret the results. A Panalytical X'Pert Pro was set up for GIXRD and used to identify the phases in the films. An incident angle of 0.8 to $2^{\circ}$ and $\mathrm{Cu} \mathrm{K} \alpha$ radiation was used in order to provide maximum resolution and intensity for the thin films, scanning a $2 \theta$ range of 18 to $75^{\circ}$. Regular powder diffraction scans where also taken on a Anton PAAR TTK 450 temperature stage on the X'pert Pro X-ray diffractometer. Initially scans were taken on films that exhibited $\beta$-phase crystal structure only over $2 \theta$ from 38 to $43^{\circ}$, as this range shows the most prominent peak change when a transformation occurs. Films were heated and cooled in the range of $450^{\circ} \mathrm{C}$ to $-150^{\circ} \mathrm{C}$ in order to collect patterns. After suitable transformation temperatures had been identified, whole pattern scans were taken in the martensitic and austenitic states. A Zeiss Supra 55 VP SEM was used to observe the topography and cross section of the films, this was done using the tilt stage and observing a clean fracture surface. A TEM cross section was also prepared using a Gatan PIPS system and observed using a JEOL FX-2010F. 


\section{RESULTS}

Although films deposited at room temperature are smooth, they are only poorly crystallised, with almost no discernible X-ray diffraction peaks. Initial attempts at increasing crystallinity in these films using heat treatment at $450^{\circ} \mathrm{C}$ in an inert environment was unsuccessful as a reaction occurred between the deposit and the Si substrate which formed new equilibrium phases. In extreme cases, cubic domains of pure Au segregated to the surface of the coating. Evidently, this $\mathrm{Au}$ was deposited from a low-melting point $\mathrm{Au}-\mathrm{Si}$ eutectic $\left(363^{\circ} \mathrm{C}\right)$ that formed during the heat treatment if the native $\mathrm{SiO}_{2}$ barrier on the $\mathrm{Si}$ was destroyed. However, attack of the substrate did not occur if the temperature during deposition was limited to $400^{\circ} \mathrm{C}$ as in this case the barrier oxide remained intact. This condition produced highly crystalline alloy films, however in this case XRR showed that the films were relatively rough in topography. The XRR patterns of the two types of film are compared figure 2 .

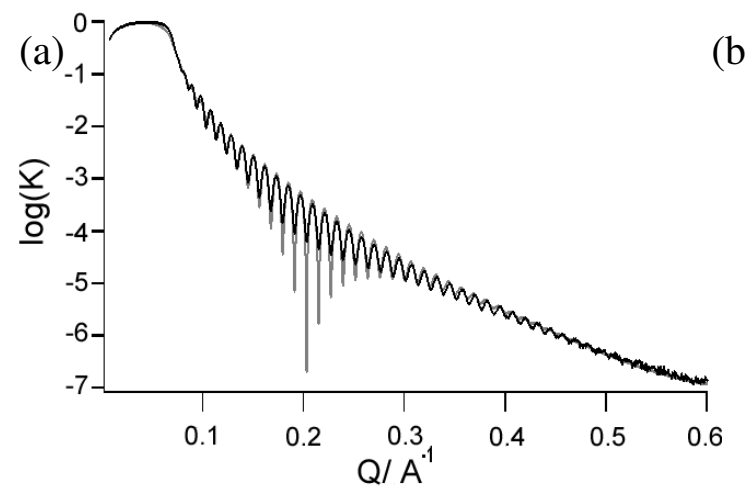

(b)

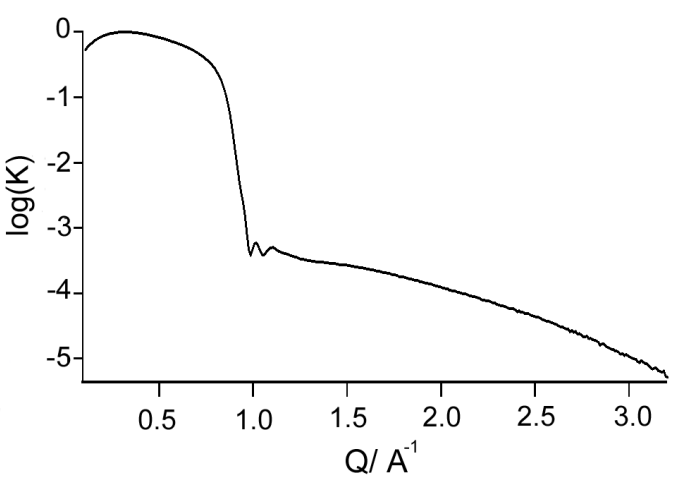

Figure 2. Reflectometry data for $\left(\mathrm{Au}_{0.58} \mathrm{Cu}_{0.42}\right)_{1-x} \mathrm{Al}_{x}$ thin films. Data black lines, fitted model, grey line. (a) Film deposited at room temperature and found by fitting of a model to have an average thickness and roughness of $49.5 \mathrm{~nm}$ and $7.8 \AA$ respectively. (b) Film deposited at $400^{\circ} \mathrm{C}$, which is too rough to generate usable interference fringes. Obtained with kind assistance of Prof. Michael James, ANSTO, Australia.

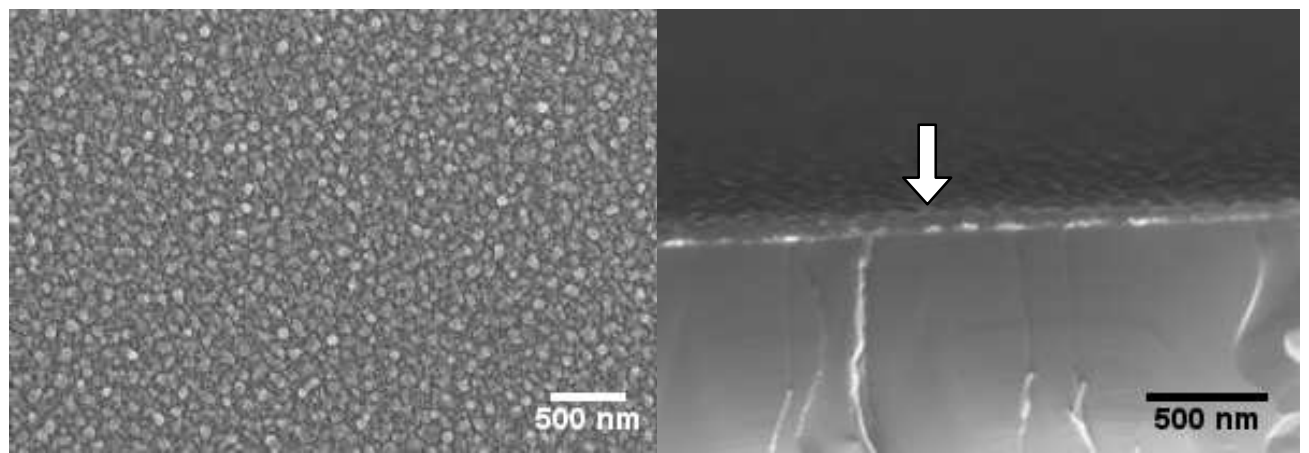

Figure 3. Topography (left) and cross-section (right) through films deposited at $400^{\circ} \mathrm{C}$. The film is indicated by an arrow. Crystallization and grain growth has occurred .

When observed under the SEM, figure 3, films deposited at $400^{\circ} \mathrm{C}$ can be seen to form a continuous layer, however individual grains protrude from the film creating an uneven surface. In the planar view these crystals can be seen to be less than $100 \mathrm{~nm}$ wide in films of approximately $40-60 \mathrm{~nm}$ thickness. In backscatter mode the film produces very little contrast, showing that it is chemically homogenous. TEM cross-sections of the crystalline films, figure 4 , 
show the uneven thickness clearly, with the majority of the profile showing clusters of large grains overlapping to form an almost continuous film of approximately $50 \mathrm{~nm}$ thickness. There is a $5 \mathrm{~nm}$ diffusion layer at the base of the film that can be identified by a change in contrast. At higher magnification, fringes spaced at about $1.54 \mathrm{~nm}$ become visible in this film. If a nominal spacing of the close-packed planes of $0.222 \mathrm{~nm}$ is accepted $[10,18]$, then a martensite phase of the $7 \mathrm{R}$ type is indicated by the presence of these fringes [10].

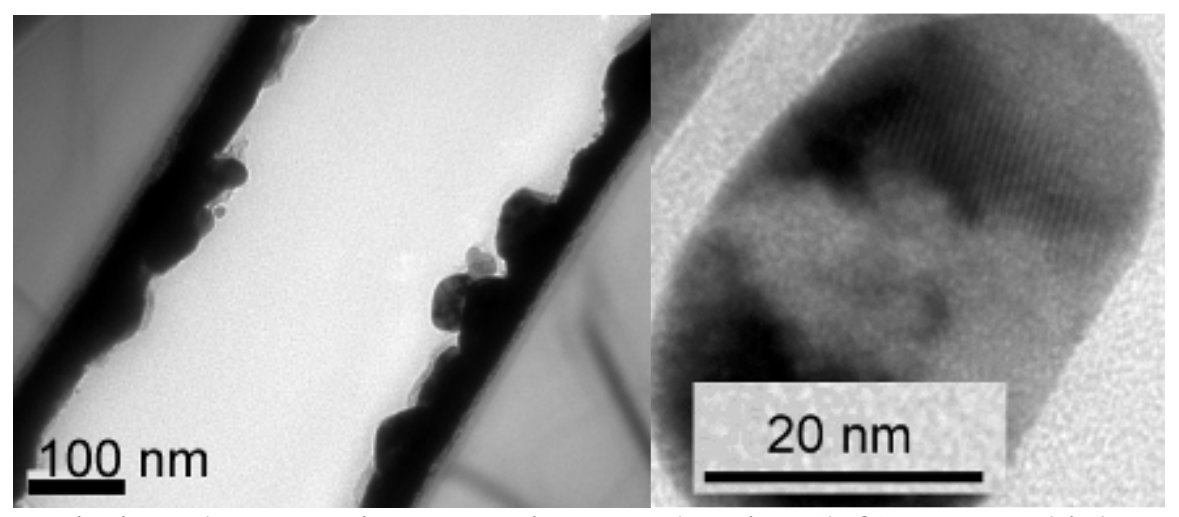

Figure 4. Transmission electron microscope images showing (left) uneven thickness of film due to crystallization and grain growth and (right) regular fringes at $1.54 \mathrm{~nm}$ spacing.

(a)

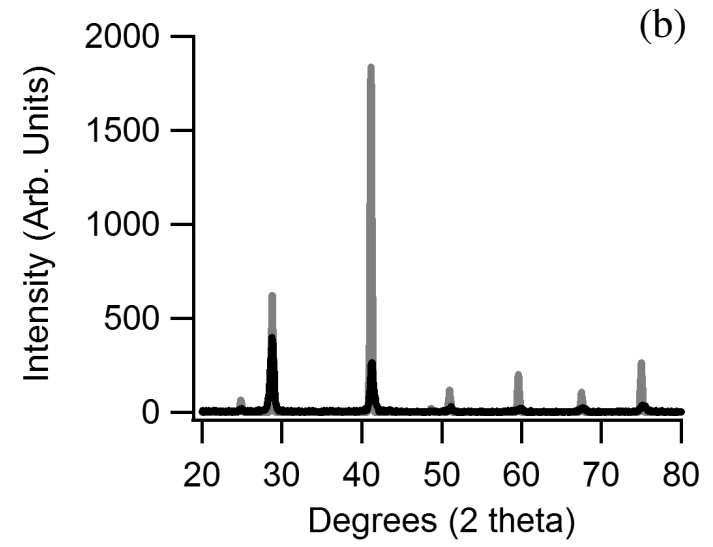

(b)

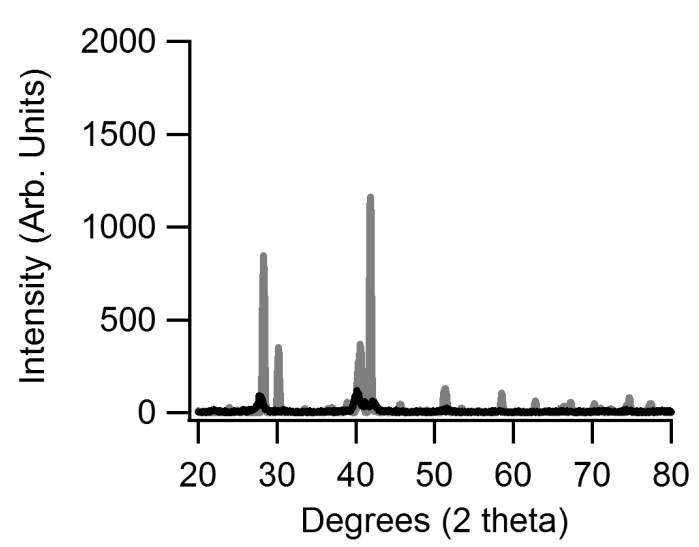

Figure 5. Calculated (grey) and measured (black) GIXRD patterns of (a) the parent and (b) martensite phase of the shape memory alloy in the form of a nanoscale thin films.

The lack of crystallinity when the $\left(\mathrm{Au}_{0.58} \mathrm{Cu}_{0.42}\right)_{1-x} \mathrm{Al}_{x}$ films were deposited at room temperature is similar to the situation found for very thin, nanoscale films of TiN [14]. In contrast, when the present films were deposited onto a substrate heated to $400^{\circ} \mathrm{C}$, the application of GIXRD revealed the presence of the $\alpha, \beta$ and $\gamma$ phases, depending on $\mathrm{Al}$ content. However, only the $\beta$ phase was sought in the present instance as the other two do not have shape-memory properties. Further samples of $\beta$ phase films of different compositions were then deposited by control of the Al content and these showed either martensite or austenite, figure 5, at room temperature. These samples were then cycled through a range of temperatures while the $\{220\}$ parent phase peak, and the related but closely positioned (1 23$),\left(\begin{array}{ll}1 & 2 \\ - & -3\end{array}\right),(200)$ and (006) martensite peaks (indexed on an orthorhombic unit cell with $a=4.474 \AA, b=5.916 \AA, c=13.330 \AA$ ) were scanned to observe the austenite and martensite transformations. Although the XRD could 
not resolve the individual martensite peaks clustered within $0.5^{\circ}$ either side of $2 \theta=41^{\circ}$, their broad convolution was clearly visible. These scans showed, figure 6 , that an example that was martensitic as fabricated possessed an austenite start $\left(A_{\mathrm{s}}\right)$ temperature of nearly $400^{\circ} \mathrm{C}$, while an example that began as austenitic in the fabricated state had a martensite start $\left(M_{\mathrm{s}}\right)$ temperature somewhere between -50 and $-100^{\circ} \mathrm{C}$.
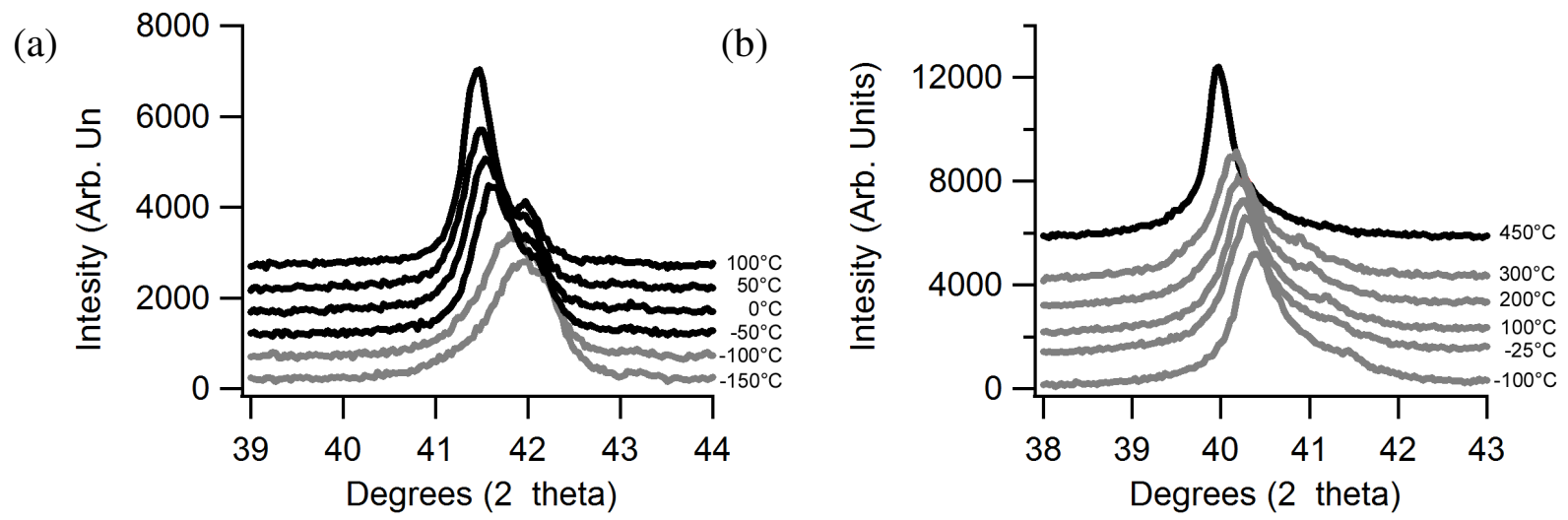

Figure 6. XRD patterns obtained from nanoscale thin films of $\left(\mathrm{Au}_{0.58} \mathrm{Cu}_{0.42}\right)_{1-x} \mathrm{Al}_{x}$, parent phase black, martensite grey (a) After deposition this sample was in the parent phase at RT and transformed to martensite at a temperature between $-50^{\circ} \mathrm{C}$ and $-100^{\circ} \mathrm{C}$. (b) This sample was martensitic at room temperature after deposition. It transformed to parent phase in the vicinity of $400^{\circ} \mathrm{C}$ when reheated.

\section{DISCUSSION}

The films produced in the present work range in thickness from 45 to $100 \mathrm{~nm}$. However, TEM and optical examination of bulk $\mathrm{Au}_{7} \mathrm{Cu}_{5} \mathrm{Al}_{4}$ shows that it contains a hierarchical microstructure consisting of micrometer-scale variants, nanometer-scale twins, and atomic-scale stacking faults, with the twins being of the order of about 100 to $200 \mathrm{~nm}$ thickness [5, 19]. This type of microstructure lowers the energy barrier to martensite formation by self-accommodating the transformation strain. Clearly, both the variants and the twins are too big to form in the present films, and therefore some change to the thermodynamics of the displacive transformations should be expected. In other SMAs it is expected that the $\mathrm{A} \rightarrow \mathrm{M}$ transformation temperature would be decreased or even completely suppressed [20]. Nevertheless, depending on composition, martensitic films have been produced here. Furthermore, both these and the austenitic films do transform when cycled through temperature. In contrast, the lack of transformation in nanoscale TiNi films has been reported to be due to either $(i)$ the formation of oxide layer and diffusion layers, both of which consume the $\beta$ phase [14], and/or (ii) a raised energy barrier due to the lack of self-accommodation mentioned earlier [20]. The first of these factors does not apply here since the TEM images showed that the films had only a $5 \mathrm{~nm}$ diffusion layer and a negligible oxide layer. Nevertheless, the transformation temperatures are at the outer envelop of temperatures cited in the literature for this system. We note that other factors may be at work quite aside from the size effect. For example, a relatively dense defect structure, pancake shape of grain, presence of oxide impurities, and residual and thermal stresses in the film may also influence the displacive transformations by pinning the austenite/martensite interfaces, while a variable $\mathrm{Al}$ content changes the $e / a$ and has a strong effect on the $M_{\mathrm{s}}$ and $A_{\mathrm{s}}$. 


\section{CONCLUSIONS}

Nanoscale films of $\mathrm{Au}-\mathrm{Cu}-\mathrm{Al}$ shape memory alloy have been deposited by magnetron sputtering over a range of stoichiometries. Films of less than $50 \mathrm{~nm}$ thickness were obtained. These still underwent the displacive transformations that are a prerequisite for the shape memory effect to occur. However, the $M_{\mathrm{s}}$ and $A_{\mathrm{s}}$ transformation temperatures were, respectively, significantly lower and higher than normally the case for these alloys. Whether this was due to a variation in $\mathrm{Al}$ content which is known to control these temperatures, or some other factor, is not yet known. Only sufficiently well crystallized films underwent the transformations. Unfortunately, well-crystallized films invariably had a rough surface texture. Further development is still needed to optimize the opposing requirements for smoothness and crystallinity in these films.

\section{ACKNOWLEDGMENTS}

The authors would like to thank AINSE Ltd for providing Award No 5597 to enable work on these SMA actuators conducted.

\section{REFERENCES}

1. I. M. Wolff and M. B. Cortie, Gold Bull. 27, 44 (1994).

2. V. K. Bhatia, C. S. Kealley, A. Dowd, F. C. Levey and M. B. Cortie, Gold Bull. 42, 201 (2009).

3. V. K. Bhatia, C. S. Kealley, R. Wuhrer, K. S. Wallwork and M. B. Cortie, J. Alloys Compd. 488, 100 (2010).

4. L. Fumagalli, S. Besseghini, F. Passarett and G. Airoldi, J. Alloys Compd. 433, 332 (2007).

5. F. C. Levey, M. B. Cortie and L. A. Cornish, J. Alloys Compd. 354, 171 (2003).

6. F. C. Levey, M. B. Cortie and L. A. Cornish, Scr. Mater. 47, 95 (2002).

7. L. Battezzati, G. Fiore and M. Massazza, J. Alloys Compd. 434/435, 264 (2007).

8. F. C. Levey, M. B. Cortie and L. A. Cornish, Metall. Mater. Trans. A. 31, 1917 (2000).

9. M. B. Cortie and F. C. Levey, Intermetallics 8, 793 (2000).

10. M. B. Cortie and F. C. Levey, Intermetallics 10, 23 (2002).

11. Y. Gu, M. Jin and X. Jin, Intermetallics 17, 704 (2009).

12. M. Jin, J. Liu and X. Jin, Intermetallics 18, 846 (2010).

13. D. Wan and K. Komvopoulos, J. Mater. Res. 20, 1606 (2005).

14. Y. Q. Fu et al., Thin Solid Films 515, 80 (2006).

15. D. Pissuwan, S. M. Valenzuela and M. B. Cortie, Trends Biotechnol. 4, 62 (2006).

16. F. C. Levey, M. B. Cortie and L. A. Cornish, Metall. Mater. Trans. A. 33A, 987 (2002).

17. A. Nelson, J. Appl. Crystallog. 39, 273 (2006).

18. F. C. Levey and M. B. Cortie, Mater. Sci. Engng A 303, 1 (2001).

19. M. J. Witcomb, R. V. Finnie and L. A. Cornish, J. Mater. Sci. Lett. 16, 674 (1997).

20. T. Waitz, T. Antretter, F. D. Fischer and H. P. Karnthaler, Mater. Sci. Technol. 24, 934 (2008). 